\title{
DESAIN MODIFIKASI PERMAINAN TRADISIONAL SEBAGAI ALTERNATIF UNTUK PEMANASAN
}

\author{
Riduansyah $^{1}$, Y. Touvan Juni Samodra ${ }^{2}$, Uray Gustian ${ }^{3}$ \\ ${ }^{1,2,3}$ Prodi Pendidikan Kepelatihan Olahraga Jurusan Ilmu Keolahragaan, Fakultas \\ Keguruan Dan Ilmu Pendidikan, Universitas Tanjungpura \\ ridwansyahptk34@gmail.com,tovan@fkip.untan.ac.id,uray.gustian@fkip.untan.ac.id
}

\begin{abstract}
The aim of this research is the development of warm-up with traditional games for students before doing sports activities. The method used is Research and Development $(\mathrm{RnD})$ with procedures for potential problem analysis, product design, expert validation, design revision, and testing. The subjects in the study were 10 students of Sports Coaching Education, from 7 sons and 3 daughters with an average age of 20 years. The instrument uses a pulse measuring test and a questionnaire. The analysis technique uses descriptive statistical calculations. The results of the judge's assessment for the first game were $98 \%$, the second game was $98 \%$ and the third game was $98 \%$, which means that the assessment of the design was categorized as "Very Worthy" to be tested. The results of this research in the student trials for game 1 , game 2 , and game 3 received a $64 \%$ rating to increase the pulse rate in the training zone from $60 \%$ to $75 \%$. It can be said that $100 \%$ of game 1 , game 2 , and game 3 increase the pulse rate.
\end{abstract}

Keywords: Warming Up, Traditional Games, Pulse.

\begin{abstract}
ABSTRAK. Tujuan dari penelitian adalah pengembangan pemanasan dengan permainan tradisional bagi mahasiswa sebelum melakukan aktivitas olahraga. Metode yang digunakan adalah Reaserch and Development $(\mathrm{RnD})$ dengan prosedur analisis potensi masalah, desain produk, validasi ahli, revisi desain dan uji coba. Subjek dalam penelitian adalah mahasiswa Pendidikan Kepelatihan Olahraga berjumlah 10 orang coba dari 7 putra dan 3 putri dengan rata-rata umur 20 tahun. Instrumennya menggunakan tes ukur denyut nadi dan angket. Teknik analisis yang menggunakan penghitungan statistik deskriptif. Hasil penilaian judge permainan pertama $98 \%$, permainan kedua $98 \%$ dan permainan ketiga $98 \%$ yang artinya penilaian dari desain termasuk kategori "Sangat Layak" untuk diuji cobakan. Hasil dari penelitian uji coba kemahasiswa permaianan 1, permainan 2 dan pemainan 3 mendapat penilaian $64 \%$ meningkatkan denyut nadi kezona latihan dari $60 \%$ sampai $75 \%$. Hal tersebut dapat dikatakan $100 \%$ permainan 1 , permainan 2 dan permainan 3 berhasil meningkatkan denyut nadi.
\end{abstract}

Kata Kunci: Pemanasan, Permainan Tradisional, Denyut Nadi.

\section{Pendahuluan}

Olahraga merupakan serangkaian aktivitas fisik yang dilakukan secara terstruktur dengan berpedoman pada aturan-aturan tertentu tetapi tidak terikat pada intensitas dan waktunya. Sedangkan, aktivitas fisik adalah segala kegiatan atau aktivitas yang menyebabkan peningkatan pengunaan energi/kalori oleh tubuh (Burhaein, 2017). Olahraga merupakan sebuah aktivitas fisik yang terstruktur dan di lakukukan terus menerus.

Aktivitas fisik dalam bentuk pemanasan merupakan hal yang paling dibutuhkan di semua cabang olahraga yang tak lain berfungsi sebagai peminimalisir resiko terjadinya cedera saat melakukan aktivitas inti. Cedera olahraga merupakan hal yang sangat 


\section{Journal Respecs \\ Research Physical Education and Sports}

Vol.3, No.2, Juli 2021, pp.20-31

p-ISSN: 2654-5233

e-ISSN: 2654-7112

menakutkan bagi seorang atlet maupun olahragawan, karena cedera akan membuat atlet kehilangan waktu mengikuti latihan dan pertandingan. Akibatnya, atlet tidak memiliki kesempatan untuk menunjukkan prestasi terbaiknya (Nurcahyo, 2010). Cedera olahraga didefinisikan sebagai cedera yang terjadi pada bagian tubuh saat seseorang berolahraga atau saat melakukan latihan fisik tertentu. Cedera Olahraga tidak hanya berupa kerusakan yang mendadak yang terjadi saat olahraga misal seperti strains dan laserasi pada jaringan lunak sistem muskuloskeletal namun, termasuk didalamnya adalah syndrome overuse (bagian tubuh tertentu rusak karena penggunaan yang berlebihan berulang kali) merupakan akibat jangka panjang dari sesi latihan dengan gerakan atau postur tubuh yang monoton dan berulang-ulang sehingga muncul manifestasi klinis (Setyaningrum, 2019). Cedera yang terjadi waktu berolahraga disebabkan oleh beberapa hal, yaitu; kecelakaan, tidak serius, pelaksanaan latihan yang kurang baik, peralatan yang tidak sesuai, kurangnya persiapan kondisi fisik serta pemanasan dan peregangan yang tidak memadai (Usra, 2012). Untuk menurunkan risiko terjadinya cedera perlu dilakukan tindakan preventif diantaranya yaitu melakukan pemanasan dan peregangan sebelum olahraga.

Ada beberapa penelitian yang mengatakan bahwa pentingnya pemanasan bagi seseorang ketika hendak melakukan aktivitas olahraga. Seperti yang di katakan oleh (Saputra, 2015) penerapan permainan tradisional dalam pemanasan berpengaruh sebesar $14,52 \%$ terhadap efektivitas pembelajaran pendidikan jasmani, olahraga dan kesehatan. Hal tersebut ada pengaruh yang signifikan terhadap pemanasan. Menurut (Huda, 2016) ada pengaruh yang signifikan pada pemanasan dengan permainan kecil yang ditunjukan dengan peningkatan $7,47 \%$.

Pemanasan perlu dilakukan karena kondisi fisiologis pada waktu istirahat berbeda dengan saat olahraga dan hendaknya sistem fisiologis tersebut tidak ditingkatkan secara tiba-tiba (Alanazi, 2016). Beberapa keadaan fisiologis yang terjadi ketika melakukan pemanasan diantaranya peningkatan aktivitas enzim dan peningkatan aliran darah kemudian pertukaran oksigen. Dengan pemanasan akan memudahkan gerakan saat berolahraga karena aliran darah akan meningkat pada suatu otot sehingga serabut otot menjadi lebih elastis (Cochrane, 2013). Beberapa gerakan persiapan tubuh untuk melakukan kegiatan yang lebih berat dengan cara melakukan beberapa latihan 


\section{Journal Respecs \\ Research Physical Education and Sports}

Vol.3, No.2, Juli 2021, pp.20-31

p-ISSN: 2654-5233

e-ISSN: 2654-7112

sederhana sebelum melakukan inti kegiatan atau latihan yang lebih berat yang disebut pemanasan. Seseorang yang akan melakukan latihan sangat penting terlebih dahulu mempersiapkan sistem fisiologis tubuhnya. Hal ini bertujuan agar dalam melakukan latihan tidak terjadi kesalahan, sehingga seseorang dengan kemampuan fisiknya masing-masing dapat latihan sesuai yang diharapkan yaitu mencapai hasil maksimal. Tujuan utamanya adalah untuk meningkatkan potensi fungsi alat-alat tubuh (fisiologis) para atlet dan untuk mengembangkan kemampuan biomotor menuju tingkatan yang tertinggi. Pada hakekatnya tujuan dari pemanasan sebagai penurunan resiko cedera saat akan melakukan kegiatan olahraga atau latihan (Magalhães et al., 2010) dan (Simatupang \& Suprayogi, 2019).

Pada umumnya pemanasan dilakukan dengan berlari ataupun aktivitas fisik yang mengakibatkan denyut nadi meningkat. Pemanasan dapat dilakukan dengan berbagai cara seperti dengan modifikasi game, permainan tradisional dan modifikasi permainan tradisional (Siahaan \& Sundhari, 2019). Yang terpenting dalam pemanasan adalah sudah siapnya indikator dalam pemasanan sebelum melakukan latihan inti yaitu, suhu tubuh meningkat, denyut jantung meningkat, keluar keringat dan lainnya yang menyebabkan tubuh siap melakukan kegiatan lebih berat. Ketika hal tersebut sudah terjadi maka sudah dapat di katakan sesorang tersebut minim resiko cedera saat melakukan latihan inti. Pemanasan merupakan salah satu bagian dasar dari program permulaan yang terdiri dari sekelompok aktifitas fisik yang dilakukan pada saat hendak melakukan latihan (Nurkadri, 2017).

Pengembangan pemanasan ini hakekatnya tidak hanya merubah bentuk atau pola gerakan tersebut, melainkan bisa membawa dimana situasi saat pemanasan lebih mengasikan dan tidak membosankan. Dengan modifikasi dari permainan tradisional sebagai pemanasan dapat di lakukan dengan efektif dan efisien (Lesmana, 2015). Pemanasan yang dapat di lakukan mulai dari yang ringan, sedang sampai yang berat. Dalam artian, mulai dari intensitas yang ringan melalui permainan tradisional tupai dan pohon, kemudian yang sedang permainan bintang beralih, lalu masuk ke yang berat yaitu permainan tangkap jadi.

\section{Metode Penelitian}




\section{Journal Respecs \\ Research Physical Education and Sports}

Vol.3, No.2, Juli 2021, pp.20-31

Metode yang digunakan dalam penelitian adalah penelitian pengembangan $(\mathrm{RnD})$ menurut (Sugiyono, 2018). Metode penelitian memberikan gambaran bagaimana rancangan penelitian yang meliputi; prosedur atau langkah-langkah yang harus dipenuhi, waktu penelitian, sumber data, dan dengan langkah apa data-data tersebut diperoleh dan selanjutnya diolah lalu dianalisis. Prosedur pengembangan penelitian meliputi analisis potensi masalah, desain produk, validasi ahli, revisi desain dan uji coba. Tahap pertama menentukan desain permainan tradisional yaitu tupai dengan pohon, bintang beralih dan tangkap jadi. Selanjutnya, desain akan dinilai oleh tiga judges. Instrumen yang digunakan dalam penelitian ini adalah tes ukur denyut nadi awal dan denyut nadi akhir saat pemanasan. Analisis data pada validasi ahli menggunakan kriteria kelayakan. Kemudian uji coba permainan pada mahasiswa Pendidikan Kepelatihan Olahraga yang berjumlah 10 orang coba terdiri dari 7 putra dan 3 putri. Teknik analisis data menggunakan IBS Statistik 20 analisis deskriptif.

Tabel 1. Persentase Ukur Denyut Nadi Maksimal Menurut (Yolanda et al., 2018)

\begin{tabular}{ccccc}
\hline \multirow{2}{*}{ No } & Umur & \multicolumn{3}{c}{ Denyut Nadi Maksimal } \\
& & $100 \%$ & $75 \%$ & $60 \%$ \\
\hline 1 & 19 Tahun & 201 & 150 & 120 \\
2 & 20 Tahun & 200 & 150 & 120 \\
3 & 21 Tahun & 199 & 149 & 119 \\
4 & 22 Tahun & 198 & 148 & 118 \\
\hline
\end{tabular}

Rumus: 220-umur $=D N \max$

\section{Hasil dan Pembahasan}

Proses pengembangan penelitian ini melalui prosedur desain permainan tradisional yang awalnya di ujikan ke orang coba mahasiswa Pendidikan Kepelatihan Olahraga (Universitas Tanjungpura) dengan banyaknya orang 10 tanpa adanya tes denyut nadi. Pembuatan desain awal pengembangan pemanasan dengan permainan tradisional sudah mendapatkan hasil rancangan permainan yang diharapkan oleh peneliti dan yang kemudian akan diuji validasi ke judge. Permainan tersebut di rancang dalam tiga tahapan level, yaitu level satu rendah (tupai dan pohon), level dua sedang (bintang beralih), dan level tiga tinggi (tangkap jadi). 


\section{Journal Respecs \\ Research Physical Education and Sports}

Vol.3, No.2, Juli 2021, pp.20-31

Pada penelitian pengembangan ini desain perancangan produk dilakukan sebanyak dua kali. Desain awal yang di rancang berupa video pola permainan yang dimainkan oleh mahasiswa tanpa adanya pengukuran denyut nadi. Pada tahap kedua desain tersebut di revisi oleh peneliti untuk mengetahui kekurangan dari permainan tersebut. Kemudian mendesain lagi permainan dengan di ujikan kepada mahasiswa kembali namun, dengan pengukuran denyut nadi awal dan sesudah dari game pertama, kedua dan ketiga. Uji coba dengan mahasiswa disini dimulai dengan menghitung denyut nadi awal dan denyut nadi setelah melakukan pemanasan. kemudian istirahat agar denyut nadi kembali normal, lanjut ke game yang kedua dengan mengukur denyut nadi awal dan sesudah dan seterusnya game ke tiga. Penghitungan denyut nadi dilakukan dengan meletakkan kedua jari telunjuk dan tengah ke pembuluh darah yang ada di leher, penghitungan dilakukan selama 10 detik. Selanjutnya dari hasil penghitungan per 10 detik dikalikan 6 untuk mendapati penghitungan selama 1 menit (60 detik).

Tabel 2. Hasil Penilaian Judge Pertama.

\begin{tabular}{|c|c|c|c|c|c|}
\hline & $\begin{array}{l}\text { Sum of } \\
\text { Squares }\end{array}$ & $\mathrm{df}$ & $\begin{array}{l}\text { Mean } \\
\text { Square }\end{array}$ & $\mathrm{F}$ & Sig. \\
\hline Between & .000 & 2 & .000 & .000 & 1.000 \\
\hline \multicolumn{6}{|l|}{ Groups } \\
\hline Within Groups & 2.700 & 27 & .100 & & \\
\hline Total & 2.700 & 29 & & & \\
\hline \multicolumn{6}{|c|}{ Tabel 3. Hasil Penilaian Judge Kedua. } \\
\hline & $\begin{array}{l}\text { Sum of } \\
\text { Squares }\end{array}$ & $\mathrm{df}$ & $\begin{array}{l}\text { Mean } \\
\text { Square }\end{array}$ & $\mathrm{F}$ & Sig. \\
\hline Between & .067 & 2 & .033 & 1.000 & .381 \\
\hline \multicolumn{6}{|l|}{ Groups } \\
\hline Within Groups & .900 & 27 & .033 & & \\
\hline Total & .967 & 29 & & & \\
\hline
\end{tabular}


Tabel 4. Hasil Penilaian Judge Ketiga.

\begin{tabular}{lccccc}
\hline & $\begin{array}{l}\text { Sum of } \\
\text { Squares }\end{array}$ & df & $\begin{array}{l}\text { Mean } \\
\text { Square }\end{array}$ & F & Sig. \\
\hline Between & .067 & 2 & .033 & 1.000 & .381 \\
Groups & & & & & \\
Within Groups & .900 & 27 & .033 & & \\
$\quad$ Total & .967 & 29 & & & \\
\hline
\end{tabular}

Dasar pengambilan keputusan dalam Analisis Anova:

a. Jika nilai signifikansi (Sig) $>0,05$ maka rata-rata sama.

b. Jika nilai signifikansi (Sig) $<0,05$ maka rata-rata berbeda.

Berdasarkan hasil penghitungan signifikansi Anova di atas, diketahui penilaian judge pertama, kedua dan ketiga $>0,05$ sehingga dapat disimpulkan bahwa penilaian desain permainan dari ketiga judge tersebut "SAMA" secara signifikan. Hal tersebut menunjukan bahwa desain dari permainan yang dinilai sudah layak atau boleh untuk di uji cobakan. Analisis yang digunakan pada penilaian judge menggunakan kriteria kelayakan, dengan hasil 98\% penilaian judge termasuk dalam kriteria Sangat Layak desain permainan tupai dengan pohon, bintang beralih dan tangkap jadi digunakan sebagai pemanasan.

Tabel 5. Hasil Ukur Denyut Nadi Awal Pemanasan Dan Akhir Pemanasan Permainan Tupai Dengan Pohon.

\begin{tabular}{lcccc}
\hline & & Umur & DN awal & DN akhir \\
\hline $\mathrm{N}$ & Valid & 10 & 10 & 10 \\
& Missing & 0 & 0 & 0 \\
Mean & & 20,80 & 81,00 & 134,90 \\
Median & 21,00 & 81,00 & 135,50 \\
Mode & 21,00 & $72.00^{\mathrm{a}}$ & $130.00^{\mathrm{a}}$ \\
Std. Dev & 1,39 & 9,48 & 4,72 \\
Range & 4,00 & 30,00 & 12,00 \\
Minimum & 19,00 & 66,00 & 129,00 \\
Maximum & 23,00 & 96,00 & 141,00 \\
\hline
\end{tabular}


Dalam tabel 5 disajikan analisis data mahasiswa rata-rata umur 20 tahun, mean denyut nadi awal 81, mean denyut nadi sesudah 134, kemudian minimal umur 19 tahun, minimal denyut nadi awal 66, minimal denyut nadi akhir 129 dan maksimal umur 23, denyut nadi awal 96, denyut nadi akhir 141.

Pertama yang dilakukan dalam uji coba oprasionalnya dengan langkah awal menghitung denyut nadi selama satu menit dari banyaknya orang coba. Kemudian melakukan pemanasan dengan permainan yang pertama yaitu tupai dan pohon, permainan tersebut dilakukan selama 5 menit dan dimainkan sebanyak 3 kali. Kemudian istirahat untuk mengembalikan denyut nadi ke normal, setelah itu hitung lagi denyut nadinya, dan lanjut ke permainan selanjutnya. Permainan yang kedua dilakukan selama 3 menit dan dimainkan 2 kali dan istirahat kembali untuk menormalkan denyut nadi dan setelah itu hitung kembali denyut nadinya. Kemudian permainan yang selanjutnya permainan yang terakhir dilakukan selama 3 menit dan dimainkan 1 kali. Hal tersebut dilakukan karena permainan perlu dilakukan lebih dari satu untuk mencapai target denyut nadi dalam zona latihan.

Tabel 6. Hasil Ukur Denyut Nadi Awal Pemanasan Dan Akhir Pemanasan Permainan Bintang Beralih.

\begin{tabular}{lllcc}
\hline & & Umur & DN awal & DN akhir \\
\hline $\mathrm{N}$ & Valid & 10 & 10 & 10 \\
& Missing & 0 & 0 & 0 \\
Mean & & 20,80 & 79,40 & 137,40 \\
Median & 21,00 & 79,50 & 138,50 \\
Mode & 21,00 & $72.00^{\mathrm{a}}$ & $138.00^{\mathrm{a}}$ \\
Std. Dev. & 1,39 & 8,52 & 3,68 \\
Range & 4,00 & 24,00 & 12,00 \\
Minimum & 19,00 & 66,00 & 129,00 \\
Maximum & 23,00 & 90,00 & 141,00 \\
\hline
\end{tabular}

Selanjutnya tabel 6 disajikan analisis data mahasiswa rata-rata umur 20 tahun, mean denyut nadi awal 79, mean denyut nadi akhir 137, kemudian minimal umur 19 tahun, minimal denyut nadi awal 66, minimal denyut nadi akhir 129 dan maksimal umur 23, denyut nadi awal 90, denyut nadi akhir 141. 
Vol.3, No.2, Juli 2021, pp.20-31

Tabel 7. Hasil Ukur Denyut Nadi Awal Pemanasan Dan Akhir Pemanasan Permainan Tangkap Jadi.

\begin{tabular}{lcccc}
\hline & & Umur & DN awal & DN akhir \\
\hline $\mathrm{N}$ & Valid & 10 & 10 & 10 \\
Mean & & 0 & 0 & 0 \\
Median & 20,80 & 81,00 & 136,50 \\
Mode & 21,00 & 81,00 & 138,00 \\
Std. Dev & 21,00 & $72.00^{\mathrm{a}}$ & $130.00^{\mathrm{a}}$ \\
Range & 1,39 & 9,48 & 4,11 \\
Minimum & 4,00 & 30,00 & 11,00 \\
Maximum & 19,00 & 66,00 & 130,00 \\
& & 23,00 & 96,00 & 141,00 \\
\hline
\end{tabular}

Pada tabel 7 disajikan analisis data mahasiswa rata-rata umur 20 tahun, mean denyut nadi awal 81, mean denyut nadi akhir 136, kemudian minimal umur 19 tahun, minimal denyut nadi awal 66, minimal denyut nadi akhir 130 dan maksimal umur 23, denyut nadi awal 96, denyut nadi akhir 141.

Berdasarkan dari ketiga tabel hasil penelitian dapat disimpulkan, diketahui mendapat hasil rata-rata dari game pertama yaitu umur (20 tahun), denyut nadi awal pemanasan (81), denyut nadi akhir pemanasan (134), kemudian memiliki minimal dan maximal denyut nadi awal pemanasan (66 dan 96), denyut nadi minimal dan maksimal akhir pemanasan (129 dan 141). Dengan jumlah orang coba 10, terdiri dari 7 orang putra dan 3 orang putri. Hasil tersebut dapat disimpulkan bahwa pemanasan menggunakan permainan 1, permainan 2 dan permainan 3 dapat meningkatkan denyut nadi ke zona latihan yaitu $64 \%$ dari rata-rata denyut nadi akhir melakukan pemanasan. oleh sebab itu, pemanasan dengan permainan tradisional tupai dengan pohon, bintang berlatih dan tangkap jadi dapat meningkatkan denyut nadi ke zona latihan dari $60 \%$ sampai $75 \%$.

Terdapat penelitian-penelitian yang terdahulu yakni (Abdul Latif Rusdi, 2018; Gandasari, 2019; Ishak, 2017; Johandi Yusuf et al., 2020; Kamaludin et al., 2020; Mahfud \& Fahrizqi, 2020; Mudzakir, 2020; Permana et al., 2018; Prasetio \& Praramdana, 2020) mengatakan dalam penelitiannya yang terdahulu yang sama dengan 


\section{Journal Respecs \\ Research Physical Education and Sports}

Vol.3, No.2, Juli 2021, pp.20-31

p-ISSN: 2654-5233

e-ISSN: 2654-7112

penelitian kali ini dalam hal pemanasan dan permainan tradisional di pembelajaran PJOK dapat disimpulkan bahwa dengan melakukan permainan tradisional dalam pembelajaran PJOK dapat meningkatkan motivasi siswa untuk berolahraga hal tersebut dapat dibuktikan dari hasil penelitian terdahulu yang memiliki penilaian berpengaruh dan Sangat Baik untuk digunakan dalam aktivitas olahraga bagi siswa. Ada penelitian yang sangat kuat untuk melihat apakah permainan tradisional ketika digunakan sebagai pemanasan dapat meningkatkan denyut nadi ke zona latihan yaitu penelitian dari (Mahfud \& Fahrizqi, 2020) dan (Hasanah, 2016). Dalam penelitiannya mengatakan bahwa permainan tradisional dapat digunakan sebagai pemanasan yang dapat dinilai $100 \%$ meningkatkan denyut nadi ke zona latihan. Berdasarkan hasil pengembangan dapat disimpulkan bahwa permainan digunakan sebagai salah satu acuan guna meningkatkan keterampilan motorik siswa. Model yang dihasilkan memiliki beberapa variasi dengan menggunakan permainan tradisional. Model ini akan meningkatkan minat anak dalam mengikuti olahraga, karena bentuk latihannya dikemas dalam bentuk permainan yang menyenangkan.

Penelitian ini jarang dilakukan, seperti pada permasalahan dalam penulisan karya ilmiah, umumnya pemanasan saat ini dilakukan hanya menggunakan joging tanpa adanya variasi. Berdasarkan hasil bukti penelitian dengan sampel mahasiswa menegaskan bahwa permainan dengan joging membosankan. Penelitian ini menyatakan selain pemanasan dengan joging, pemanasan juga bisa dilakukan dengan menggunakan model permainan tradisional yang intinya dapat meningkatkan denyut nadi untuk selanjutnya melakukan aktivitas olahraga inti.

Keterbatasan penelitian. Pada penelitian ini orang coba dalam prosedur uji coba produk masih terbatas, dikarenakan keterbatasan waktu dan tempat. Dalam penelitian ini peran guru olahraga tidak dilibatkan dalam penilaian langsung mengenai pemanasan yang sering dilakukan, melainkan hanya menjadi judge. Penelitian pengembangan ini tidak melibatkan pengaruh peningkatan motorik.

\section{Kesimpulan}

Hasil dari penelitian pengembangan dikategorikan Sangat Layak dengan penilaian oleh judges 98\% untuk digunakan sebagai alternatif pengganti pemanasan dengan permainan tradisional dan akan lebih menyenangkan ketika melakukan pemanasan. 


\section{Journal Respecs \\ Research Physical Education and Sports}

Vol.3, No.2, Juli 2021, pp.20-31

Hal ini dapat dilihat dari hasil penilaian uji coba dengan capaian denyut nadi mahasiswa 136. Penelitian ini mendapat desain permainan yaitu tupai dengan pohon permainan 1, bintang beralih permainan 2 dan permainan 3 tangkap jadi.

\section{Saran}

Berdasarkan penelitian pengembangan yang telah menyatakan bahwa desain rancangan penelitian sudah layak dan divalidasi oleh judges, maka terdapat saran bagi pelaku olahraga diharapkan dapat memanfaatkan pengembangan pemanasan dengan permainan tradisional ini, agar tidak hanya joging ketika pemanasan. Diharapkan ke depannya ketika ingin meneliti pengembangan pemanasan dengan permainan tradisional dapat mengikutsertakan peran guru dalam penilaian pemanasan yang dilakukan saat itu. Diharapkan penelitian ini selanjutnya dapat dikembangkan dengan melibatkan pengaruh terhadap peningkatan motorik bagi siswa.

\section{Daftar Pustaka}

Abdul Latif Rusdi. (2018). No Title. Permainan Tradisional Sebagai Alternatif Pemanasan Olahraga Sekaligus Peningkatan Fleksibilitas Siswa. Permainan Tradisional Sebagai Alternatif Pemanasan Olahraga Sekaligus Peningkatan Fleksibilitas Siswa., 464. Https://Doi.Org/10.33365/.V1i1.622

Alanazi, H. M. (2016). Role Of Warming-Up In Promoting Athletes Health And Skills. International Journal of Scientific And Research Publications, 6(1), 156-2250. Https://Doi.Org/10.29322

Burhaein, E. (2017). Aktivitas Fisik Olahraga Untuk Pertumbuhan Dan Perkembangan Siswa Sd. Indonesian Journal Of Primary Education, 1(1), 51-58. Https://Doi.Org/10.17509/Ijpe.V1i1.7497

Cochrane, D. (2013). The Sports Performance Application Of Vibration Exercise For Warm-Up, Flexibility And Sprint Speed. In European Journal Of Sport Science (Pp. 256-271). Https://Doi.Org/10.1080/17461391.2011.606837

Gandasari, M. F. (2019). Pengaruh Permainan Olahraga Tradisional Sepak Beleg Terhadap Kemampuan Kelincahan Anak Usia 7-10 Tahun. Jurnal Ilmu Keolahragaan, 2(1), 27-31. Https://Doi.Org/10.26418/Jilo.V2i1.32628

Hasanah, U. (2016). Pengembangan Kemampuan Fisik Motorik Melalui Permainan Tradisional Bagi Anak Usia Dini. Jurnal Pendidikan Anak, 5(1), 717-733. Https://Doi.Org/10.21831/Jpa.V5i1.12368

Huda, A. (2016). Pengaruh Pemanasan Dengan Permainan Kecil Terhadap Passing Bawah Bola Voli. 4(2), 321-326. Https://Ejournal.Unesa.Ac.Id/Index.Php/JurnalPendidikan-Jasmani/Issue/Archive 


\section{Journal Respecs \\ Research Physical Education and Sports}

Vol.3, No.2, Juli 2021, pp.20-31

p-ISSN: 2654-5233

e-ISSN: 2654-7112

Ishak, M. (2017). Latihan Olahraga Dalam Permainan Tradisional. Jurnal Ilmu Keolahragaan, $14(2)$,

$42-48$.

Https://Doi.Org/Https://Doi.Org/10.24114/Jik.V14i2.6113

Johandi Yusuf, Muhammad Muhyi, \& Yoso Wiyarno. (2020). Pengembangan Pemanasan Dinamis Dalam Pembelajaran Pendidikan Jasmani Olahraga Dan Kesehatan (Pjok) Tingkat Sekolah Menengah Pertama. Jurnal Kejaora (Kesehatan Jasmani Dan Olah Raga), 5(1), 79-85. Https://Doi.Org/10.36526/Kejaora.V5i1.762

Kamaludin, K., Ngadiman, N., Festiawan, R., Kusuma, I. J., \& Febriani, A. R. (2020). Pengembangan Permainan Pecah Piring Sintren: Pemanfaatan Olahraga Tradisional Pada Pembelajaran Untuk Meningkatkan Kemampuan Motorik Kasar Anak. Tegar: Journal Of Teaching Physical Education In Elementary School, 3(2), 37-45. Https://Doi.Org/10.17509/Tegar.V3i2.24447

Lesmana, S. I. (2015). Hubungan Antara Karakteristik Atlet Dengan Masa Pemulihan Setelah Cidera Olahraga. Jumal Fisioterapi, 15(1), 45-51. Https://Doi.Org/10.1177/000276428102500110

Magalhães, T., Ribeiro, F., Pinheiro, A., \& Oliveira, J. (2010). Warming-Up Before Sporting Activity Improves Knee Position Sense. Physical Therapy In Sport, 11(3), 86-90. Https://Doi.Org/10.1016/J.Ptsp.2010.06.001

Mahfud, I., \& Fahrizqi, E. B. (2020). Pengembangan Model Latihan Keterampilan Motorik Melalui Olahraga Tradisional Untuk Siswa Sekolah Dasar. Sport Science And Education Journal, 1(1), 31-37. Https://Doi.Org/10.33365/.V1i1.622

Mudzakir, D. O. (2020). Pengaruh Permainan Olahraga Tradisional Penjas Di Sekolah Dasar. Jurnal Pendidikan Jasmani Kesehatan Dan Rekreasi, 10(1), 44-49. Https://Doi.Org/10.35194/Jm.V10i1.941

Nurcahyo, F. (2010). Pencegahan Cedera Dalam Sepak Bola. Medikora, 6(1), 65-76. Https://Doi.Org/10.21831/Medikora.V0i1.4670

Nurkadri, N. (2017). Perencanaan Latihan. Jurnal Prestasi, 1(2), 13-22. Https://Doi.Org/10.24114/Jp.V1i2.8059

Permana, R., Nugraha, M. F., Hendrawan, B., Pratiwi, A. S., Nurfitriani, M., \& Saleh, Y. T. (2018). Sosialisasi Olahraga Tradisional Untuk Meningkatkan Kebugaran Dan Minat Siswa Sd Terhadap Pembelajaran Olahraga Di Wilayah Kecamatan Tamansari. Abdimas: Jurnal Pengabdian Masyarakat, 1(1), 1-6. Https://Doi.Org/10.35568/Abdimas.V1i1.233

Prasetio, P. A., \& Praramdana, G. K. (2020). Gobak Sodor Dan Bentengan Sebagai Permainan Tradisional Dalam Pembelajaran Penjasorkes Berbasis Karakter Pada Sekolah Dasar. Pedagogi: Jurnal Penelitian Pendidikan, 7(1), 19-28. Https://Doi.Org/10.25134/Pedagogi.V7i1.2858

Saputra, K. R. (2015). Penerapan Permainan Tradisional Dalam Pemanasan Terhadap Efektivitas Pembelajaran Pendidikan Jasmani, Olahraga Dan Kesehatan. 3(2), 288-292. 


\section{Journal Respecs \\ Research Physical Education and Sports}

Vol.3, No.2, Juli 2021, pp.20-31

Https://Ejournal.Unesa.Ac.Id

Setyaningrum, D. A. W. (2019). Cedera Olahraga Serta Penyakit Terkait Olahraga. Jurnal Biomedika Dan Kesehatan, 2(1), 39-44. Https://Doi.Org/10.18051/Jbiomedkes.2019.V2.39-44

Siahaan, J. M., \& Sundhari, S. (2019). Studi Pemanfaatan Huma Betang Tumbang Manggu Sebagai Sumber Pembelajaran Olahraga Tradisional Di Kalimantan Tengah. Riyadhoh: Jurnal Pendidikan Olahraga, 2(2), 1-10. Https://Doi.Org/10.31602/Rjpo.V2i2.2476

Simatupang, N., \& Suprayogi, M. K. (2019). Survey Cedera Olahraga Pada Atlet Sepak Bola Pplp Sumatera Utara. Sains Olahraga: Jurnal Ilmiah Ilmu Keolahragaan, 3(1), 55-65. Https://Doi.Org/10.24114/So.V3i1.13062

Sugiyono. (2018). Metode Penelitian Kuantitatif, Kualitatif Dan Rnd. Afabeta.

Usra, M. (2012). Cedera Dalam Cabang Olahraga Beladiri Dan Teknik Mengatasinya. Jurnal Ilmu Olahraga Dan Kesehatan, 2(1), 18-27. Https://Repository.Unsri.Ac.Id/Id/Eprint/16423

Yolanda, R., Nurhayu, A., \& Gumay, J. R. (2018). Model Pembelajaran Bola Basket Melalui Modifikasi Sarana Dan Prasarana Untuk Meningkatkan Denyut Nadi Maksimal Siswa Kelas V Sekolah Dasar. Journal Physical Education, Health And Recreation, 2(2), 161-168. Https://Doi.Org/10.24114/Pjkr.V2i2.9587 